\title{
Response: "Commentary: Mental distress in patients with cerebral visual injury assessed with the German Brief Symptom Inventory"
}

\author{
Carolin Gall ${ }^{1,2 *}$, Doreen Brösel ${ }^{2}$ and Gabriele H. Franke ${ }^{1}$ \\ 'Department of Rehabilitation Psychology, AHW, Magdeburg-Stendal University of Applied Sciences, Stendal, Germany, \\ ${ }^{2}$ Department of Psychiatry, AMEOS Hospital, Haldensleben, Germany
}

Keywords: mental health, quality of life, cerebral visual injury, coping with disease, mental distress, visual field defects

A response to

Commentary: "Mental distress in patients with cerebral visual injury assessed with the German Brief Symptom Inventory"

by Craig, A. (2015). Front. Aging Neurosci. 7:122. doi: 10.3389/fnagi.2015.00122

OPEN ACCESS

Edited by:

Lia Fernandes,

University of Porto, Portugal

Reviewed by:

Marcelo Fernandes Costa,

Universidade de São Paulo, Brazil

*Correspondence:

Carolin Gall,

carolin.gall@hs-magdeburg.de

Received: 30 June 2015

Accepted: 31 July 2015

Published: 17 August 2015

Citation:

Gall C, Brösel D and Franke GH

(2015) Response: "Commentary:

Mental distress in patients with

cerebral visual injury assessed with

the German Brief Symptom Inventory."

Front. Aging Neurosci. 7:158.

doi: 10.3389/fnagi.2015.00158
In his valuable commentary on our recent publication Ashley Craig pointed out that the observed "strong connection between mental distress and a disorder like cerebral visual injury is highly important for directing future research in the area." Within this context we wish to emphasize another significant factor: patients' quality of life that may be relevant as a potential mediator variable.

Besides generic health-related quality of life, vision-related quality of life as assessed with questionnaires such as the National Eye Institute-Visual Functioning Questionnaire (NEI-VFQ, Mangione et al., 2001) are important factors that may help to explain why some patients develop mental health impacts after cerebral injury while others do not. The NEI-VFQ may be used to gather information on how patients with visual field loss after lesions to the visual pathway are able to cope with daily visual tasks. For brain-damaged patients the NEI-VFQ may be ideally conducted together with a neuroophthalmological supplement which is available in English and German (Raphael et al., 2006; Wagenbreth et al., 2011).

Recently, we have observed that a higher extent of vision-related quality of life in patients with cerebral visual injury was related to lower levels of mental distress (Gall et al., 2013). We further hypothesized that the maintenance respectively elevation of vision-related quality of life could reduce and prevent mental distress due to vision problems. Thus, patients with persisting visual field defects may benefit from rehabilitation aiming at the development of individualized coping strategies. With a greater repertoire of coping strategies for visual demands in everyday life visionrelated quality of life is likely to increase which may eventually translate into improved mental health.

Dr. Craig also highlighted the other side of the hypothesis, i.e., that "quality of life will improve should mental health problems be addressed" (Gall et al., 2015). In fact, it is very probable that the respective interventions - of which too few are being made available to visually impaired patients in need-may have a positive influence on both mental health and quality of life.

As pointed out in the commentary, very similar phenomena of elevated mental distress have been observed in patients with physical disorders after damage to the central nervous 
system (Craig, 2015). A next step forward may be to go beyond a cross-sectional methodology in order to study the occurrence of mental health problems with an economic questionnaire approach in longitudinal studies, for instance using the Brief Symptom Inventory (BSI, Franke, 2000), together with disease-related quality of life instruments,

\section{References}

Craig, A. (2015). A commentary on "Mental distress in patients with cerebral visual injury assessed with the German Brief Symptom Inventory." Front. Aging Neurosci. 7:122. doi: 10.3389/fnagi.2015.00122

Franke, G. H. (2000). BSI. Brief Symptom Inventory - German Version. Manual. Göttingen: Beltz.

Gall, C., Brösel, D., and Franke, G. H. (2015). Mental distress in patients with cerebral visual injury assessed with the German Brief Symptom Inventory. Front. Aging Neurosci. 7:51. doi: 10.3389/fnagi.2015.00051

Gall, C., Brösel, D., and Sabel, B. A. (2013). Remaining visual field and preserved subjective visual functioning prevent mental distress in patients with visual field defects. Front. Hum. Neurosci. 7:584. doi: 10.3389/fnhum.2013.00584

Mangione, C. M., Lee, P. P., Gutierrez, P. R., Spritzer, K., Berry, S., and Hays, R. D. (2001). Development of the 25-item National Eye Institute Visual Function Questionnaire. Arch. Ophthalmol. 119, 1050-1058. doi: 10.1001/archopht.119.7.1050

Raphael, B. A., Galetta, K. M., Jacobs, D. A., Markowitz, C. E., Liu, G. T., Nano-Schiavi, M. L., et al. (2006). Validation and test e.g., in post-stroke patients who likely suffer from sensory and physical symptoms at the same time. For the patients' benefit these studies should comprise an interventional approach targeting either neurological rehabilitation including designated coping strategies and/or psychotherapeutic interventions.

characteristics of a 10-item neuro-ophthalmic supplement to the NEIVFQ-25. Am. J. Ophthalmol. 142, 1026-1035. doi:10.1016/j.ajo.2006. 06.060

Wagenbreth, C., Sabel, B. A., Tönnies, S., and Gall, C. (2011). [The neuroophthalmic supplement to the NEI-VFQ: test statistics and validation with a cohort of patients with pre- and postchiasmatic damage]. Klin. Monbl. Augenheilkd. 228, 971-978. doi: 10.1055/s-00291246062

Conflict of Interest Statement: The authors declare that the research was conducted in the absence of any commercial or financial relationships that could be construed as a potential conflict of interest.

Copyright (C) 2015 Gall, Brösel and Franke. This is an open-access article distributed under the terms of the Creative Commons Attribution License (CC BY). The use, distribution or reproduction in other forums is permitted, provided the original author(s) or licensor are credited and that the original publication in this journal is cited, in accordance with accepted academic practice. No use, distribution or reproduction is permitted which does not comply with these terms. 